\title{
LA CATEDRAL DE ZACATECAS Y EL ARTE DEL VIRREINATO *
}

\section{Por Manuel Toussaint. ${ }^{1}$}

Existen edificios que encierran gran importancia para el movimiento artístico de la colonia, independientemente de su propio mérito artístico. La antigua parroquia de Zacatecas, edificada suntuosamente por la liberalidad de los mineros zacatecanos y convertida más tarde en catedral, es uno de ellos.

Es interesante observar que los constructores de este monumento parece que tenían en la mente la idea de una catedral cuando sólo levantaban una parroquia. Así lo indican sus tres anchurosas naves, sus tres soberbias portadas y sus torres, levantadas más tarde.

Anteriores al actual existieron dos templos parroquiales por lo menos. Su historia no es tan clara como fuera de desearse, pero procuraremos consignar los datos verfdicos más importantes. El primer cura párroco que se menciona es el Lic. Fernando Maldonado de 1558 a 1562. Parece que su templo fue provisional o de poca importancia ya que en la primera de las fechas Zacatecas llevaba diez años de fundada. ${ }^{2}$

El nuevo templo fue construido según parece de 1567 a 1585 pero, arruinado a principio del siglo xviI, fue comenzado otro hacia 1612 y

* En este año el Instituto de Investigaciones Estéticas cumple cuarenta años de existencia. Nada más oportuno para tal acontecimiento que la publicación de este trabajo inédito de don Manuel Toussaint, quien fuera aparte de uno de sus fundadores, su director por varios lustros.

En el estilo tan personal de Toussaint para escribir la historia del arte, está redac tada la historia de la catedral de Zacatecas, monumento clave de la arquitectura hispano mexicana; dada la fecha de su redacción (1948) se consideró indispensable agregarle algunas notas que con fina erudición escribió don Federico Sescosse, quien ha entregado el original para que se publique en los Anales. X. M.

1 Este es el texto de una conferencia leída en ausencia del autor durante la primera Asamblea de Mesa Redonda del Congreso de Historia, organizada por don Antonio Pompa y Pompa en septiembre de 1948 en la ciudad de Zacatecas. El licenciado don Gonzalo Obregón encontró recientemente el manuscrito entre los papeles de don Manuel Toussaint y lo obsequió amablemente al autor de estas notas. Se publica con el beneplácito de la señora Margarita Latapi Vda. de Toussaint, su heredera.

2 La fundación de Zacatecas no se hizo nunca "de juré". "De facto" ocurrió en los últimos meses del año de 1547 al colocar Diego de Ibarra la primera piedra de "la casa fuerte" necesaria para defenderse de los indios hostiles que lo cercaban y poder iniciar la explotación de las minas y la construcción de la primera "Hacienda de beneficio" de minerales. Véase: Federico Sescosse, "Nueva Luz sobre la fundación de Zacatecas" en Letras Potosinas Núm. 139, enero-marzo de 1961. 
concluido en 1625. Duró bastantes años, casi un siglo, y se dice que su arquitecto fue Francisco Jiménez.

Para principios del siglo xvir se encontraba deteriorado y en 1718 se comenzó la obra del actual monumento que fue solemnemente dedicado del 14 al 17 de agosto de 1752. Tenía sólo el primer cuerpo de la torre del lado sur y la gran fachada principal. ${ }^{3}$ Las portadas laterales parecen ser posteriores pues no figuran en la descripción publicada por el padre Miqueo en 1752, en su libro acerca de la dedicación. ${ }^{4}$

Sin duda continuaron los trabajos, pues la torre fue concluida; se labraron las dos bellas portadas laterales. 5 La parroquia continuó con la torre norte inconclusa hasta 1904, en que el maestro Dámaso Muñetón. de Jerez, copió fielmente la torre existente, levantando lo faltante para completar el conjunto de la iglesia. Antes, en 1844 fue sustituida la vieja cúpula colonial, por otra en que se imitó de modo infeliz la que corona el templo de Loreto en la ciudad de México.

El templo recibió categoría catedralicia en 1862.

La catedral de Zacatecas ofrece una planta de cruz Iatina y dos naves laterales de bóvedas más bajas. Las de la central son de arista y aquellas vaídas. La cúpula descansa sobre un tambor octogonal y los soportes son grandes pilares de sección cuadrada que reciben medias muestras de orden toscano, cuyo fuste ofrece un ornato en zig zag de relieve en

3 Sobre la corona del Padre Eterno existe una piedra que tiene en sus tres lados labrada la siguiente inscripción: $A$ bril $24 / d e$ 1775/Años. Fecha de la terminación del imafronte.- El dia ocho de septiembre de 1625 puso la primera piedra de este templo don Diego Estrada Carbajal y Galindo, Marqués de Uluapa, Chantre de Guadalajara y Visitador del Obispado.- P. José Utrera. El Templo de la Vida /Sermón/ que en la dedicación de la Iglesia y Templo parroquial de la Muy Leal, Ilustre y Noble Ciudad de Zacatecas... predicó el día 17 de agosto de 1752 / el... de la Compañía de Jesús, Rector de su colegio.- Habiéndose comenzado a construir de una sola nave para convertirse a la planta de tres definitiva cuya traza se hizo el 11 de febrero de 1728. Mariano Bezanilla, Mier y Campa, Muralla Zacatecana, México 1788.

4 Bachiller Gabriel Miqueo: Breve descripción/ del Templo o Iglesia Parrochial Mayor/ de la muy Noble y Leal Ciudad de Nuestra/ señora de los Zacatecanos/ y succinta relación/ de las fiestas con que se solemnizó su dedicación/ Por el Br.... México 1753.

5 El P. José de Utrera (op. cit., p. 26) dice: "Dedicase este templo, estando todavía sin acabar perfectamente, pues (como vemos) le falta el retablo mayor, le faltan varios colaterales, le falta el adorno interior y el exterior de una de sus portadas, y le falta la mayor parte de sus torres. ¿Y es posible que se tiene (sic) que dedicar con tantas faltas o con faltarle tanto? - $\mathrm{Si}$; porque dedicarlo en el estado que se halla, es el mejor arbitrio, que pudo tomar la siempre industriosa economía, para que todas essas faltas passen brevemente a ser sobras." 
el primer tercio. El coro se halla a los pies del templo y descansa en un arco de cinco centros.

Los altares son modernos y de mal gusto, y sobre la cornisa se ha organizado un pasillo con barandal y perillones que afea bastante la arquitectura, pues impide ver el arranque de los arcos. ${ }^{8}$ De sus ornatos antiguos parece que este interior sólo conserva las bellas claves de los arcos, tanto torales como formeros. 7

Al fondo queda la sacristía, que ocupa el espacio de la nave centra] más el de la Epístola; a la otra nave corresponde una estancia.

E1 imafronte de la catedral de Zacatecas semeja un gran escudo dividido en tres grandes fajas que corresponden a sus tres cuerpos. Acaso la concepción original no haya sido esa, como veremos, pero es así como se presenta ante nuestra ansiosa mirada. Las curvas amplias y dignas de su remate recuerdan, a no dudarlo, la forma de los escudos nobiliarios en su parte superior.

El primer cuerpo corresponde a la portada principal del templo. El arco de ingreso es doble: complícase el interior en curvas y contracurvas, en tanto que el exterior, semicircular, presenta un contorno desgarrado. A cada lado aparecen tres robustas columnas, salomónicas a partir del primer tercio de su fuste, más recargadas de ornatos en todo él, y en las entrecalles en que se abren nichos, dos de cada lado, una minucia asiática o indígena. Los capiteles de las columnas parecen dobles porque el arquitrabe también cubierto de ornatos sigue los entrantes y salientes: dijérase que nos ofrecen tres capiteles, porque el friso sufre igual vértigo. La cornisa es vigorosa, volada lo necesario para marcar sin lugar a dudas la división de los cuerpos.

Desplántase el segundo sobre un ático que sigue entrantes y salientes, y prolonga hacia lo alto la estructura inferior. Sobre las columnas de los límites extremos yérguense otras semejantes dentro del mismo complejo salomónico ornamentado al máximo, ya con igual decoración todas ellas, puesto que sus proporciones no permiten otra cosa. Las dos columnas centrales varían de motivo: no existen ornatos a modo de fajas enrolladas en su fuste; son decoraciones vegetales que se elevan

6 Fue quitado por el autor de estas notas durante el año de 1958 sicndo Obispo el doctor don Francisco Javier Nuño, juntamente con la cantoría la escalera de caracol de hierro y la ventana del testero puestas por el señor Obispo don Migucl de la Mora en 1904 y pagadas, como el segundo cuerpo de la torre norte, por Pepita Brilanti.

7 Y el marco interior del rosetón, exquisitamente labrado. 
en anillos, una sobre otra, hasta alcanzar el capitel. Este sigue la forma de sus compañeros corintios ornamentados y no aparecen dobles como los de abajo, sino dejando sólo un pequeño espacio, dígase arquitrabe, para soportar el gran friso recargado de relieves y su cornisa, bien acusada pero menor que la del cuerpo bajo.

Los mismos nichos con santos aparecen aquí, 8 pero, para darles el énfasis que requieren a su altura, se acentúa lo volado de las ménsulas. El motivo central de este segundo cuerpo y principal de toda la fachada es una gran rosa cubierta en su circunferencia de ornatos que se extienden a todo el ámbito en que se encuentra. ${ }^{9}$

El tercer cuerpo ostenta igualmente su ático, pero sólo en el espacio que comprenden las dos columnas allegadas al centro, las cuales pierden ya su característica salomónica para ostentar los exteriores fustes cubiertos de relieves, y las otras en una especie de cariátide que desarrolla trabajosamente su papel bajo el peso de tantos ornatos.

Todavía al centro entre dos pilastras, confundidas igualmente por el relieve, se abre un nicho con ménsula y su correspondiente estatua.

Este tercer cuerpo ofrece también su entablamiento completo interpretado a la manera barroca: un remedo de arquitrabe, friso y cornisa mucho menos acentuada que en los cuerpos inferiores. Su corte da a veces la idea que no fue terminada o que sufrió deterioro. ${ }^{10}$

8 En uno de los del primer cuerpo se aloja la estatua de San Pablo, la cual se simboliza con un libro en el que se lee esta curiosa inscripción: DE AM/AR A DIO/S CE GAN/A EL SCIE/LO I DICE/SAN PAB/LO QUE TODO/ ESTO ES CI/ERTO/ QUE CON PENITENCIAS/ CE GAN/AN DE PR. ST.- Los últimos caracteres ¿serán la abreviatura del nombre de un cantero?; ¿o quizá del arquitecto?- ¿deberán leerse SEPR. FT.? o sea SEPR FECIT, como lo sugiere el padre Jesús López de Lara?

9 Es curioso el hecho de que Toussaint le conceda tan poca importancia a esta "Gran Rosa" que es sin duda, el elemento más relevante en la composición del imafronte. Ignora la presencia de los magnificos relieves de los cuatro padres de la Iglesia Latina, San Gregorio en el ángulo superior izquierdo, San Gerónimo en el derecho, San Agustín en el inferior izquierdo y San Ambrosio en el último con una inexplicable oradación perfectamente circular en la punta de la nariz. La reja, de nueva factura (1964), se pudo reconstruir gracias a fotografias antiguas y a haber encontrado dos de los barrotes radiales originales. La clave, con su bellísima custodia, a la cual sirve de pie un interesante ángel atlante de alas enroscadas y cuerpo labrado a la manera primorosa de los Dvrapalas de Halebid, India; con sus grecas laterales de querubines y sus dos alegres angelillos turiferarios, constituye un conjunto escultórico de excepcional interés.

10 En efecto, el vuelo de la cornisa del tercer cuerpo, restaurado en 1964, fue "rasurado" por los años de 1880 a 1890 por el Canónigo Arcadio Delgado a causa de que, por haberse caldo una piedra, con peligro para los transeuntes, decidió cortar de raíz el peligro. 


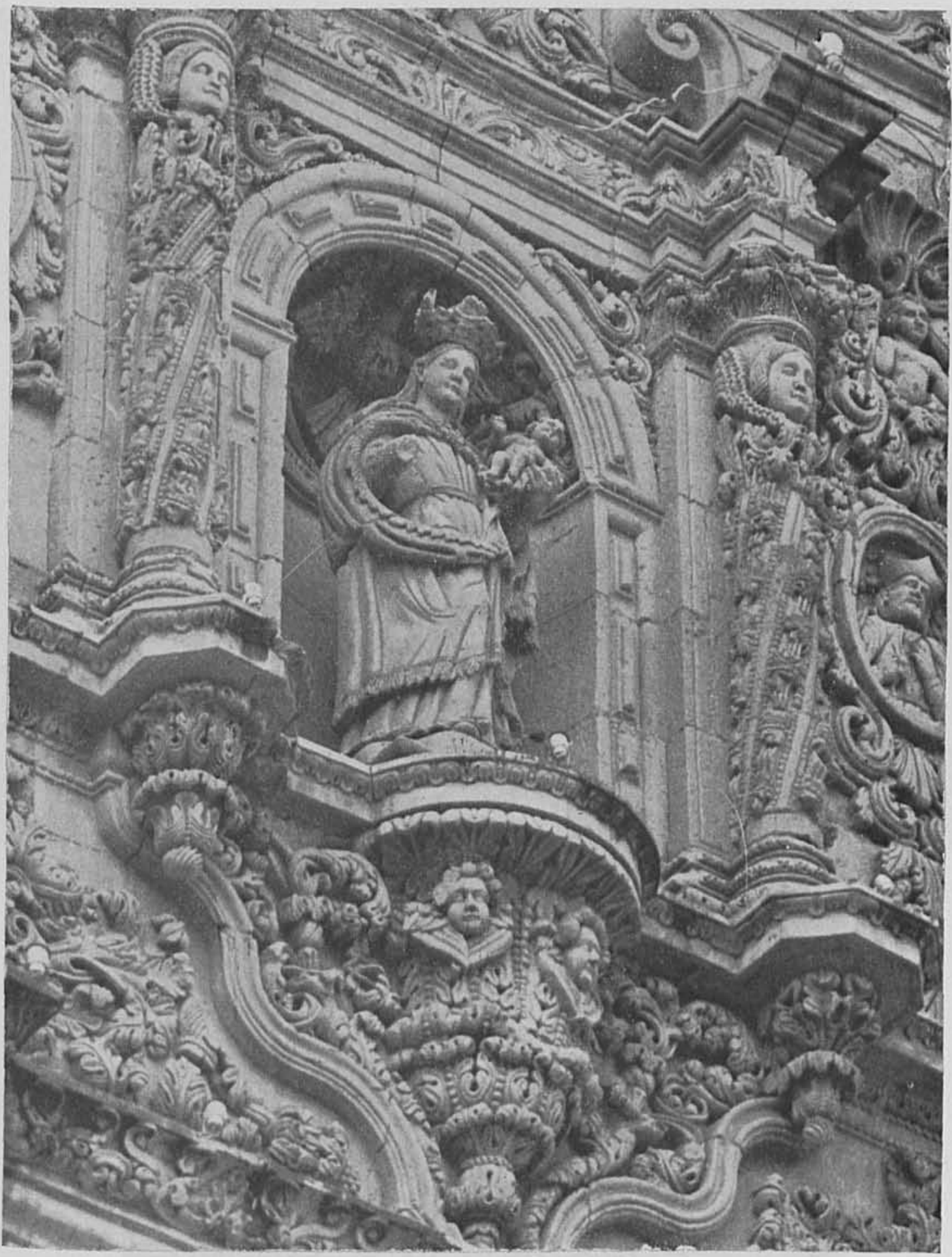

1. Zacatecas, Zac. Catedral. Detalle de la portada. 


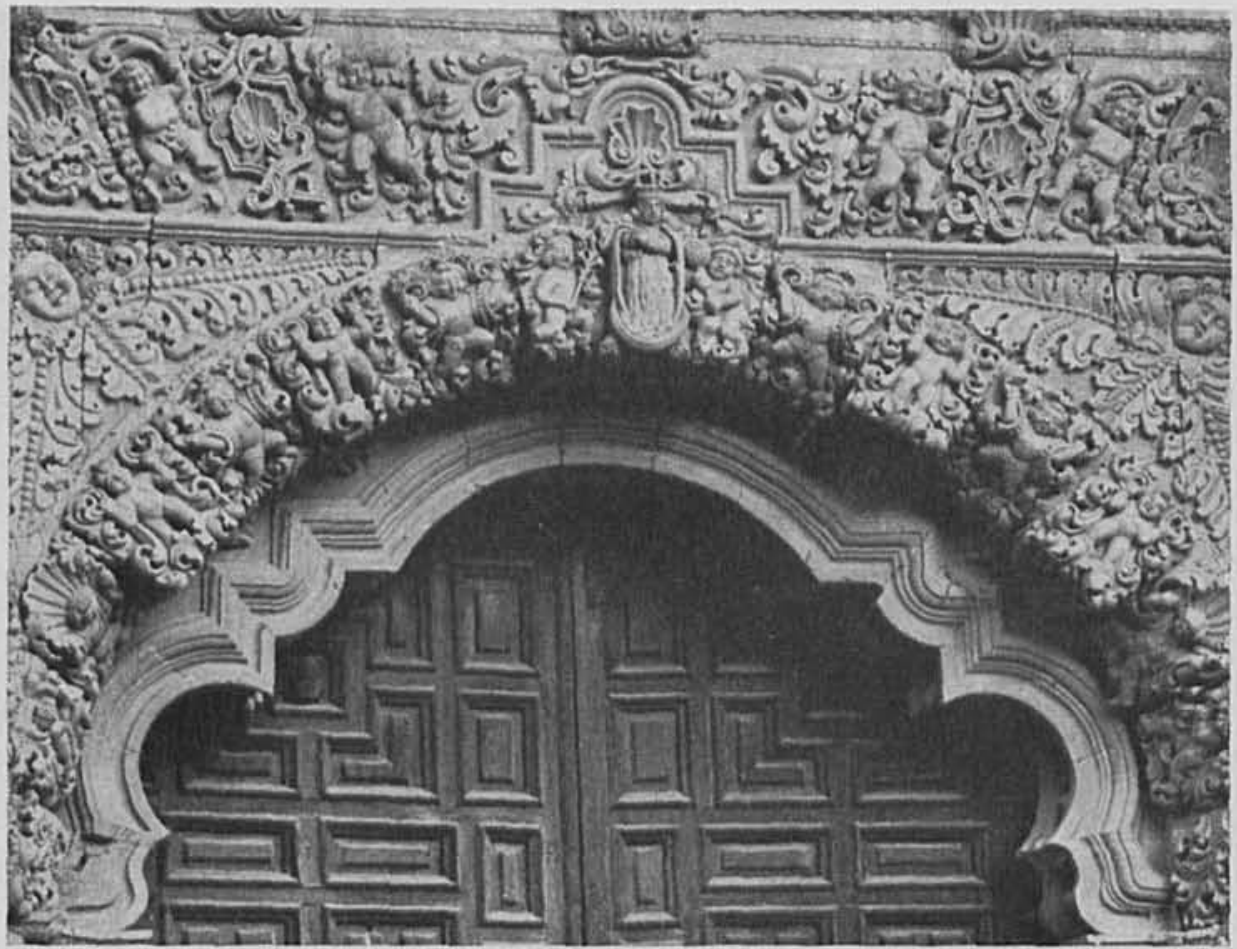

2. Zacatecas, Zac. Catedral. Arco de la puerta principal.

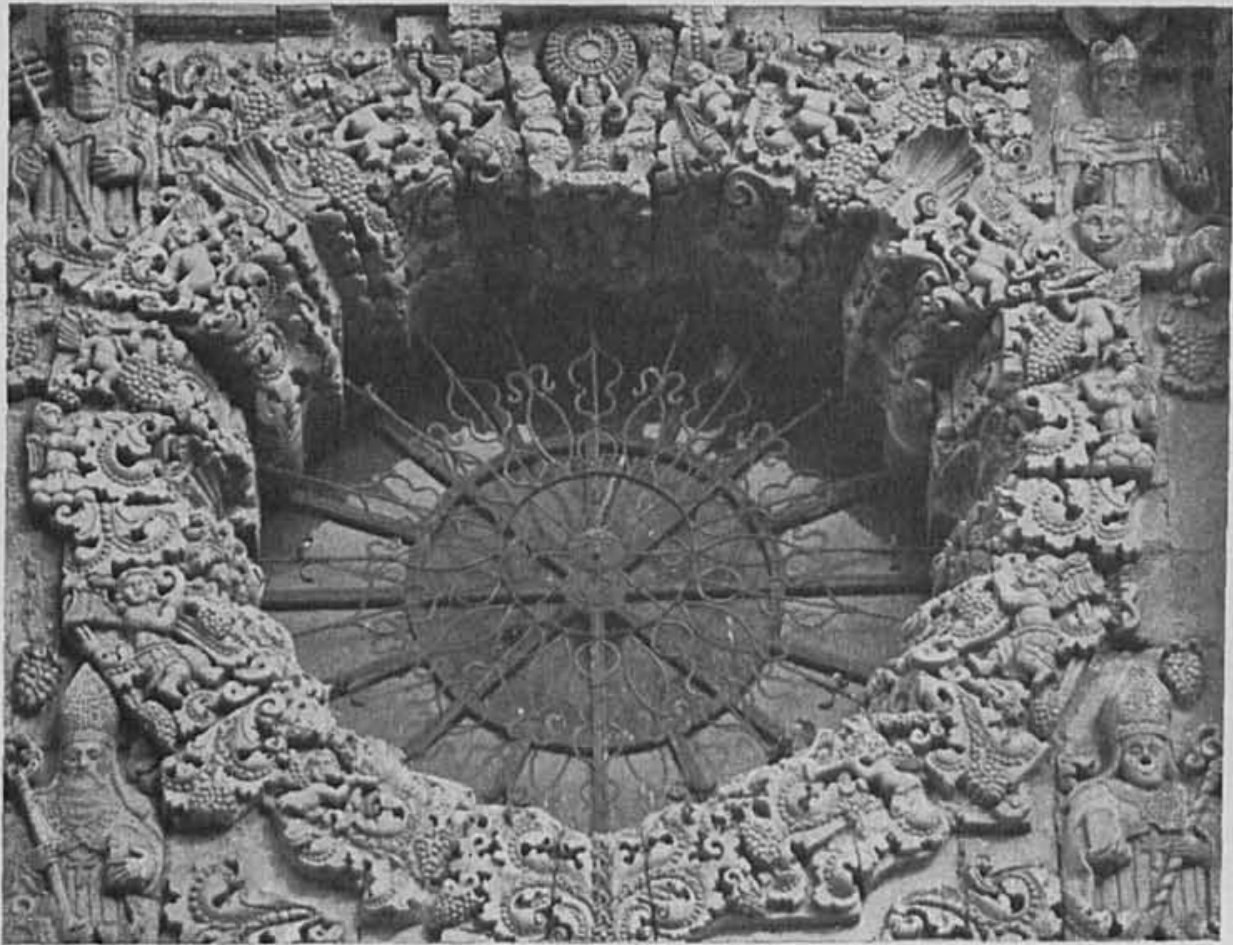

3. Zacatecas, Zac. Catedral. Ventana del coro. 
DOI: http://dx.doi.org/10.22201/iie.18703062e.1975.44.1007

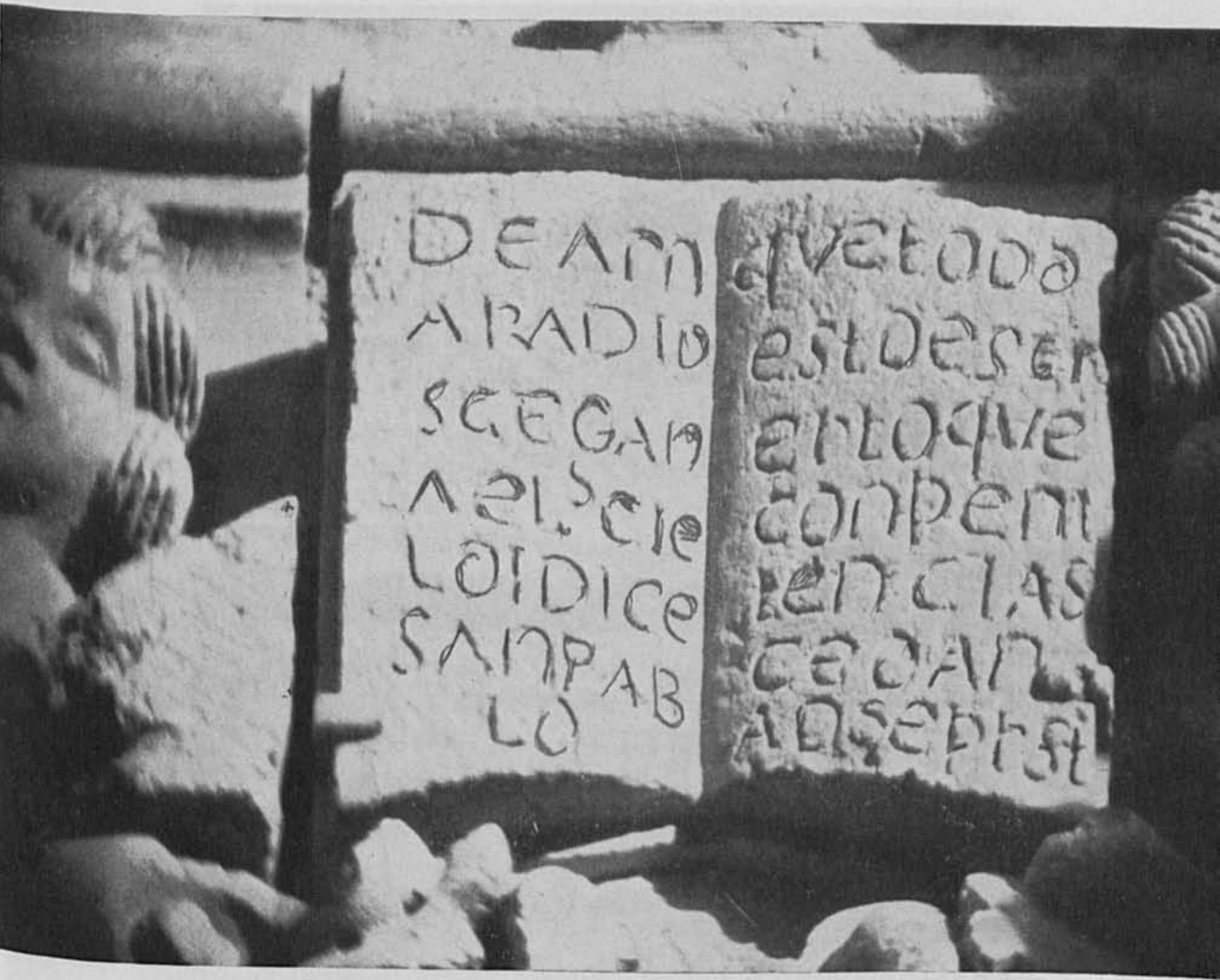

4. Zacatecas, Zac. Catedral. Inscripción en la escultura de San Pablo. 

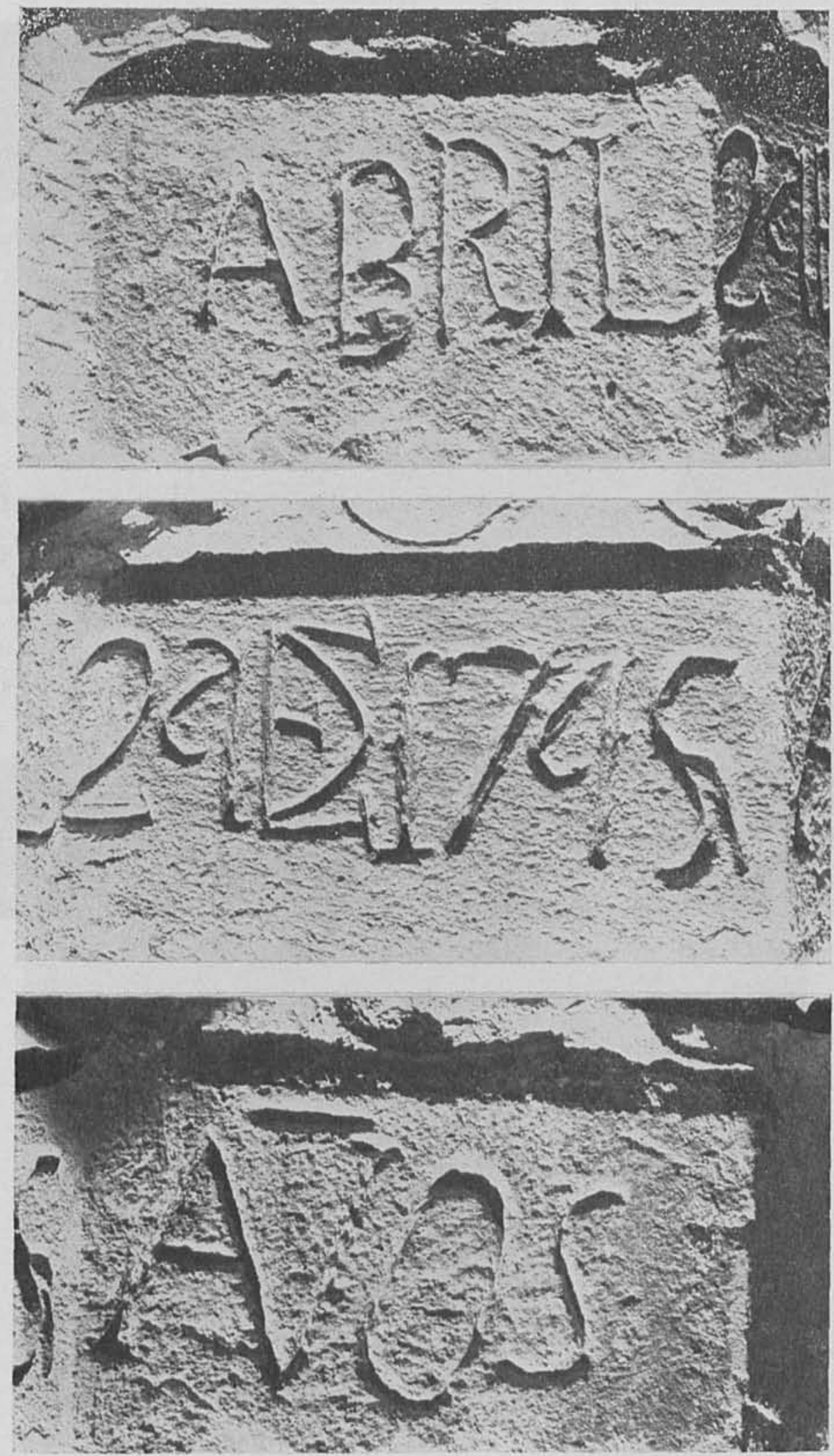

5. A. B. C. Zacatecas, Zac. Portada. Fecha de su terminación: Abril / 24 de 1745 / Años 
En los extremos del tercer cuerpo, donde ya no se prolongan las columnas inferiores, aparecen grandes perillones o remates y lo mismo debería esperarse sobre la cornisa última, coronando sus resaltos. Pero no. Desde la cornisa del segundo cuerpo, atrás de esos remates de que hemos hablado, arranca una vigorosa faja de ornatos vegetales que se prolonga en forma de escudo, como hemos dicho, y termina en la cúspide con dos róleos separados. ${ }^{11}$ Todo el espacio que cobijan está cubierto por vigorosos relieves vegetales que dan, empero, una sensación de aplanamiento diversa de lo demás. El Padre Eterno en un nicho con corona remata la fachada.

La portada del lado sur es totalmente distinta. Dentro de un barroco riquísimo parece más europea, más mesurada, más dentro de los canónes arquitectónicos. Su puerta de medio punto con jambas y rosca ornamentados con vigorosos medallones de entalladuras geométricas presenta un aspecto único. La encuadran dos vigorosas columnas adosadas a anchos pilastrones. Ellas presentan un fuste ornamentado con fuertes relieves. El entablamiento es perfecto, salvo un friso esculpido a la altura de los capiteles corintios. Después viene perfecto: arquitrabe, friso y cornisa. Es ésta amplia para marcar una división de sombra entre dos cuerpos.

El segundo consta de un ático con sus resaltos correspondientes a los lados para recibir las columnas y, fuertes relieves al centro, en que se ve un repisón para la Virgen, que constituye el motivo principal. Las columnas son salomónicas sin que el ornato que las caracteriza como tales llegue al capitel (detalle éste que se nota igualmente en las columnas inferiores) y ofrecen en este lugar medallones ovalados con figuras de santos sacerdotes. El nicho central está formado por dos columnas-cariátides que sostienen el entablamiento que se ve coronado por ornatos. Ofrece el nicho arco de medio punto con tableros realzados en su perímetro. Una buena escultura de la Virgen con el Niño, copia de la de Nuestra Señora de los Remedios de Zacatecas, se yergue en el sitio.

11 Estos róleos fueron malamente restaurados en 1965 juntamente con la corona del Padre Eterno la cual se labró, con poca fortuna, para sustituir a una muy pequeña que a su vez había sustituido a la original en 1904 cuando se coloco, con dinero de Pepita Brilante, el remate postizo con cruz de hierro de esa época y un letrero que decia "In Hoc Signo Vinces".

Cabe recordar que originalmente, entre los róleos, existió otra cruz de hierro forjado de afamada belleza, desaparecida en el siglo pasado (Miqueo op cit.). 
Los espacios libres entre nicho y columnas se ven ocupados por grandes medallones ovalados con relieves que representan santos sacerdotes, Los medallones ostentan flecos hacia abajo y se ven coronados por ornatos en relieve cuyo motivo central es un niño o ángel sobre cuya cabeza se explaya una venera.

El entablamiento del segundo cuerpo es tan perfecto como el de abajo; sobre la cornisa se yerguen, a los extremos, dados para estatuas y perillones hoy desaparecidos, y al centro una cruz trabajada en piedra tan finamente que parece filigrana. ${ }^{12}$

Si la portada lateral que hemos descrito difiere enormemente de la principal, recordando el barroco rico de mediados del siglo xvII, la que mira al norte no sólo es diversa sino exótica. El cuerpo bajo revela un ordenamiento más sobrio, con su arco de medio punto y su entablablamiento sencillo.

El segundo cuerpo es un verdadero retablo popular en que la ingenuidad, la falta de escala en las figuras, lo arcaizante del conjunto, se dan la mano para ofrecernos algo delicioso.

Un amplio ático, con dos resaltos en los extremos y tres faldones vigorosamente esculpidos al centro, soportan el retablo. Lo encuadran sobre los resaltos dos pilastras estípite, sobrias, casi incipientes. Fuera de ellas, a los lados, en el propio paramento del muro de cantera cortada, se ven dos figuras en alto relieve, remembranza arcaica y entrañable de nuestro siglo xvi.

Las pilastras estípite sostienen un entablamiento perfecto, con veneras convexas en los resaltos que a ellas corresponden, salvo que la cornisa se ve rota al centro con dos volutas que dejan libre un espacio entre ellas: se trata de dar sitio en la parte superior, a la corona de un baldaquino que cobija a la imagen central. En efecto, draperías de piedra se descuelgan aferrándose a la arquitectura, separan abajo del arquitrabe y cuelgan paralelas a los estípites. En el fondo se descubre otra tela imitada en piedra, en menudos pliegues, como si fuera seda.

12 Carlos Nebel, en su Viaje pintoresco y arqueológico sobre la parte más interesante de la Republica Mexicana (1836) trabajando sobre apuntes que llevó consigo a Europa, dibujó "El interior de la Plaza Mayor de Lacatecas" en donde se ve la portada sur de la Catedral con un remate piramidal de contorno mixtilíneo, desaparecido poco después. Hasta 1963 se conservaron en su lugar las piedras de los pedestales que ocupaban los ángeles que hoy descansan directamente sobre la cornisa y que evidentemente formaron parte de dicho remate de factura anterior a la portada actual por lo cual suponemos que debieron formar parte de la tercera iglesia. 
Hemos descrito un trono. El trono para el Santo Cristo de Zacatecas cuya reproducción allí puede verse. Imagen de arte un tanto popular cuyo cendal, por pudor, ha sido transformado en enagüilla, con sus brazos dolorosamente tensos y el chorro de sangre brotando de la fecunda herida. A los lados, humildemente más pequeños, la Virgen y San Juan sobre ménsulas esculpidas que sostienen ángeles, que parecen orar. ${ }^{13}$

El remate es acaso lo más arcaizante de la portada: todo él está limitado por una vigorosa faja de molduras que, siguiendo un perfil barroco sobrio, concentra la atención en el tema. Representa a la Santísima Trinidad como nunca ha sido representada. Concepción casi genial, esculpe en la parte superior al Padre Eterno en un vigoroso alto relieve. A sus pies la Divina Paloma, el Espíritu Santo, en forma heráldica, con las alas extendidas, custodiada por dos ángeles risueños. El Hijo, Cristo, aparece en un Divino Rostro, abajo de la paloma, en una vigorosa máscara que se destaca sobre un paño plegado. Fajas y róleos completan la composición admirable.

Las torres de la catedral de Zacatecas son esbeltas y airosas. Compónense de dos cuerpos y un remate. En cada una de ellas se abren dieciseis campaniles.

El cubo o basamento en que descansan concluye en una cornisa; sobre ésta se levanta uno a modo de ático con vigorosos entrantes y salientes arriba del cual se ve una como peana formada por un grueso moldurón y motivos ornamentales en relieve que siguen la misma curva saliente y luego rehundida. Así se forma un basamento para el primer cuerpo, que está constituido por ocho columnas adosadas y ocho pilastras: éstas en los ángulos y a los extremos de los ejes, y aquellas cerca de las esquinas. Tanto unas como otras presentan un original ornato, pues las columnas llevan fajas en relieve que recuerdan el de la parte alta de la fachada principal, las cuales cubren la parte central del fuste en dos cuartos, en tanto que el cuarto inferior es liso y el alto acanalado; y las pilastras con fuerte resalto, también en su centro. Los capiteles son originales, pues no pertenecen a ningún orden, pero si se encuentra un arquitrabe, un friso y una cornisa sobre la que descansa el segundo cuerpo de la torre.

13 Ambas portadas laterales corresponden a Ios altares principales de las naves procesionales. Esta del Santo Cristo, del que tanto se podria hablar y la del sur de Nuestra Señora de los Zacatecas; son la representación escultórica en cantera, de las originales de madera que, con devoción se vencran dentro de sus respectivos nichos de cristal. 
El mismo partido se encuentra aquí; igual ático o plinto con resaltos correspondientes a los de abajo, las mismas columnas y pilastras en disposición semejante, pero exentas, e idéntico entablamiento y remate, si bien la cornisa es menos volada, naturalmente.

El remate se halla convenientemente remetido y consta de un ático de planta octogonal cuyos lados correspondientes a los ángulos son más pequeños. Frente a cada ángulo se ve un perillón. Las ocho caras ostentan bellos óculos mistilíneos y corre alrededor una cornisa doble que sostiene el banco del cupulín y éste, separado por una moldura y con gruesos nervios exteriores que marcan sus paños revestidos, así como el banco de azulejos azules y blancos.

La linterna es graciosa, constituida por ocho columnillas salomónicas con su correspondiente entablamiento bien destacado, una perilla sobre cada resalto, y arriba un pequeño casquete esférico, con los mismos azulejos y rematado por una cruz veleta de hierro de forja.

La cúpula, como hemos dicho, es una copia poco feliz de la del templo de Loreto en México. Compónese de un gran tambor octogonal constituido por contrafuertes de piedra cortada que se despliegan en contracurvas con relación al domo y dejan un paso abajo, a modo de botareles. Entre ellos se desplantan estructuras muy renacentistas compuestas por tramos de entablamiento que arrancan de pilastras adosadas y descansan en columnas toscanas. Se forma sobre éstas un arco de perfil sobrealzado con un cornizuelo y un remate. Sobre los contrafuertes, macetones, y de allí arrancan fajas en bisel que marcan la división en paños de la cúpula. Linternilla semejante a la de las torres, pero mucho más pobre, y cruz, sin veleta, de hierro forjado.

Debemos justificar nuestro juicio. Desde luego, el criterio. La iglesia de Loreto de México es una iglesia-cúpula. Todo en ella está sujeto, dominado por la cúpula. La catedral de Zacatecas es una iglesia-fachada: la cúpula resulta insignificante. Enseguida detalles de técnica. Compárase la seguridad maestra de la cúpula de Loreto con los tanteos no resueltos que aquí vemos. Además, la escala. Esta viene a ser una cupulita de Loreto.

Afortunadamente no rompe la armonía ni la unidad del templo acaso por su misma parsimonia. $Y$ aporta un toque neoclásico en contraste, sin choque, con el barroco del resto.

El estilo de la fachada principal puede ser afiliado sin género de duda al que florece en Nueva España desde mediados casi del siglo 
XVII hasta el primer tercio del xvirr: el barroco exuberante. Es acaso esta obra cumbre en exteriores la que constituye el fin de la serie, pues, como hemos podido ver, data de mediados del mismo setecientos.

Se trata de estructuras que obedeciendo todavia al ordenamiento clásico así en proporciones aproximadas, miembros arquitectónicos afiliados a los órdenes, elementos que indican el deseo de respetar y hacer visible el sistema constructivo, lo cubren todo de ornatos en relieve $y$ se toman libertades insospechadas.

El afán de no dejar un espacio libre de ornatos, el horror al vacio, característico de los pueblos orientales que se prolonga a América en sus diversos tipos étnicos, es el que produce estos monumentos barrocos: se permiten el lujo de conservar un remedo de las líneas clásicas pero se toman todas las libertades posibles para producir una decoración extraordinaria en riqueza y exuberancia.

La portada del lado sur parece más arcaizante: recuerda el barroco rico del siglo xvir en que el ornato se ve concentrado y aparecen pequeños espacios lisos: las traspilastras de las columnas, los entablamientos, con que dan énfasis a sus partes. El claroscuro es más vigoroso, ditinguimos mejor los miembros arquitectónicos y su ordenamiento que es más claro, más simple, más razonable.

La portada del lado del norte revela tal mezcla de influencias que no podemos calificarla sino como arqueológica. El medievalismo de la la parte alta, esa Santísima Trinidad exótica que nos trae a la memoria los relieves de las posas de Calpan o de la capilla abierta de Tlalmanalco, lo mismo que los ángeles adosados al muro, contrastan con el criterio popular que campea en ese calvario, en ese Cristo fuera de escala con relación a sus acompañantes y aun a los motivos ornamentales que lo rodean. A pesar de esta diversidad de estilos es, por su ingenuidad, deliciosa.

Las torres aparecen dentro de un barroco también especial. Aunque se les encuentre semejanzas de detalle con otras torres de su época, ellas son personales, como si quisieran no confundirse con el gran escudo que están custodiando. No son desmesuradas en su altura, no aniquilan el conjunto, saben desempeñar su papel.

Ostenta pues este templo prócer cinco elementos diversos en sus estilos, como en una serie que fuese del barroco del xvII de la portada sur, al barroco exuberante de la gran fachada, al peculiar de las torres, 
hasta el neoclásico de la cúpula, pasando por el entrañable espíritu popular de la portada norte.

Pero esos cinco estilos, acaso por el sitio en que se encuentran los elementos que los ostentan, no aparecen como seres fríos, como cadáveres disecados de un museo. Todos ellos vibran al unísono de su época en una sola creación de gran vitalidad.

Para la historia del arte de México constituye la catedral de Zacatecas el último gran monumento u obra maestra del barroco en el norte del país.

\section{BIBLIOGRAFfA}

ArLegui, Fr. Joseph. Chrónica de la Provincia de N.S.P.S. Francisco de Zacatecas México, 1737.

Mrqueo, Br. D. Gabriel. Breve descripción de el templo o iglcsia parrochial mayor de la muy Noble y Leal ciudad de Nuestra Señora de los Zacatccas, México, 1753.

Bezanilla, Don Joseph Mariano Estevan de. Muralla Zacatecana, México, 1788. Mota Padilla D. Matias de la. Historia de la Conquista de la Provincia de la Nueva Galicia. Guadalajara, 1856.

Varios. Apéndice al Diccionario Universal de Historia y de Geografia. Tomo III. México, 1856.

Tello Fr. Antonio. Crónica Miscelanea Santa provincia de Xalisco. Guadalajara, 1890.

AMAdor, Elias. Bosquejo Histórico de Zacatecas, 2a edición, Zacatecas, 1943.

Dávira Garibi, José Ignacio. La Sociedad de Zacatecas en los albores del régimen colonial, México, 1939.

Salinas de la Torre, Gabriel. Testimonio de Zacatecas. México, 1946. (Valiosa reproducción de documentos antiguos, indispensables para conocer la historia de Zacatecas en la época del virreinato.) 